\title{
Context Aware Mobile Service Deployment Model of Agricultural Information System for Indian Farmers
}

\author{
Chandrasekaran S \\ Sri Ramanujar Engineering College \\ Anna university, Chennai, India
}

\author{
Dipesh Dugar M \\ M.N.M Jain Engineering College \\ Anna University, Chennai, India
}

\author{
Jitendra Kumar Jain D \\ M.N.M Jain Engineering College \\ Anna University, Chennai, India
}

\author{
Kamlesh Jain S \\ M.N.M Jain Engineering College \\ Anna University, Chennai, India
}

\author{
Dinesh Kumar Jain N \\ Sri Ram Engineering College \\ Anna University, Chennai, India
}

\begin{abstract}
The objective of the paper is to propose a context aware mobile service deployment model to deliver the needed information to the farmers in planning their agricultural activities. The application developed based on this model utilizes the GSM networking of mobile devices to bring the details to the farmers using location awareness features. A context aware service deployment model for information retrieval is achieved and the various contexts can be updated in the mobile servers. The information regarding the agriculture like nature of fertile lands, healthy seeds, proportion of fertilizers and pesticides are made available to the farmers that will enable them to take correct decisions in their pre and post harvesting activities. Since the literacy rate of farmers is low in developing countries, a special GSM device is emulated so as to reduce the number of interactions between the farmers and the services through visual buttons only. The emulated GSM based mobile phone with only a few specific buttons for the fundamental information like soil details, healthy seeds, favorable climatic conditions and suitable harvesting period. This information is made available to them at reasonable cost without heavily forcing them to interact with the agricultural experts. The model is implemented using J2ME using Eclipse IDE with HTTP server.
\end{abstract}

\section{Categories and Subject Descriptors: H3.4}

[context]: types -different requests

General Terms: Algorithms, Design

Keywords: Location awareness, Agricultural Information System, Context Awareness, Distributed Database, Device Emulation

\section{INTRODUCTION}

Agriculture Information System (AIS) is designed to coordinate the activities along with the resource information needed to complete agro processes such as sowing, watering and harvesting to assist the farmers. The information regarding the agricultural resources like fertile lands, healthy seeds, proportionate fertilizers and efficient pesticides is to be made available to the farmers that will enable them to take correct decisions in the pre and post harvesting activities without the need to interact with the agricultural experts in different geographic locations. With the advancement of current information technology, developing a personalized, user-centric system is now becoming more essential [2]. There are different agricultural methods followed in different areas based on the soil and the crops. One goal of context-aware computing is to acquire and utilize information about the contexts to provide services that are appropriate to the particular people, place, time and events [4]. Context-awareness helps to get and utilize information about the physical and social situation in which users and their wireless handset devices are embedded in order to provide improved services that are appropriate to the particular user in the given interaction platform encompasses place, time, environment, and surrounding events [2]. Hence the information retrieval from the distributed databases has to be achieved with minimum interactions. In earlier deployment, the want of reaching the information to the farmers in all areas lead researchers to communicate through HAM network. The information generated during the HAM Radio interaction paves way for follow up actions with the help of extension functionaries, active farmers. This includes a) imparting specific training to farmers at village site itself b) Organizing lectures on specific topics of interest to farmers through HAM network c) Timely broadcasting of information of wider interest through local radio stations and publication in local newspapers d) Arranging interactive discussion with farmers, extension staff, and other stakeholders and e) fore-casting for planning agricultural operations, pests and disease control. They must be empowered to decide which crop to grow, what seeds to use, whether they take organic farming or use chemicals, whom to sell and at what price. On the government side, its administrative machinery should provide services, techno- 
infrastructure and access to market, while scientists and agricultural universities should step in with technology and tools. As in the case of exporters and industries, the farmers may be encouraged to grow more by offering incentives such as smart cards to those who sell their products to the government, vital inputs to go for multiple or diverse crops and direct access to markets without middlemen so as to make them a part of the inclusive growth process. All the above setups still could not make the ultimate use of technology for the benefit of farmers. Farmers get knowledge through exchange of information, sharing of experience and expertise advice, but still they are not able to enhance the productivity due to lack of information at right time. Information unavailability and unreliable information lead the farmers to wrong decisions and even if all the agricultural activities are being executed perfectly, then farmers do not get right place to sell their products for a decent profit. In addition to this the unexpected natural disturbances and insects attacks on the fields reduces total turnover. Hence the present work focuses on the Context Aware Mobile Services and their deployment for Agricultural Information System (AIS). AIS is implemented through modified GSM device with embedded intelligence. Service oriented architecture based mobile services are extended to the end user's dedicated devices through adaptability, location awareness, mobile information access, low cost continuous services and auto identification of the mobile client.

\section{CONTEXT AWARE COMPUTING MODEL IN AIS}

Let the agriculture information space be represented as a concept cube with the vertices representing the various contexts of information retrieval. Let the query point of a farmer be " $\mathrm{f}$ " with the coordinates in the concept cube is represented as $f(x, y)$ assuming that the farmer is in the same physical space $p(x, y)$. That is $p(x, y)=f(x, y)$ meaning the farmer is in the same location whose details are sought. Context can be divided into external and internal contexts. External context means social or physical context that can have impact on physical behavior. Internal context can be acquired by interference of user's behavior and external context. The proposed agricultural system is based on external context to approach context awareness [5]. If the query of the client is initially in a context represented by the position $f(x$, y) in the concept cube and if it changes to another point in the information space, say $\mathrm{f}(\mathrm{x} 1, \mathrm{y} 1)$, then the context migration is applied by which all the edges present in that current plane are taken into account. The possible edges that lead to the desired context point must be considered. Then the current context point $\mathrm{f}(\mathrm{x} 1, \mathrm{y} 1)$ is compared with the possible edges that leads to $(\mathrm{x} 1, \mathrm{y} 1)$ and whichever edge is nearest to the context point $f(x 1, y 1)$ is chosen in context migration. This will improve the efficiency of migration from one context to another and hence will reduce the context aware computation time. As a result, the information retrieval time will be reduced and will be available in the handheld device of the client more quickly.

The planes that encompass the concept cube are as follows:

Plane P1 - Profit Edge E1=1-2 Edge E7=6-5

Plane P2 - Planning Edge E2=2-3 Edge E8=6-7

Plane P3 - Period Edge E3=3-4 Edge E9=7-8

Plane P4 - Policy Edge E4=4-1 Edge E10=8-5

Plane P5 - Product Edge E5=5-3 Edge E11=1-7

Plane P6 - Process Edge E6=4-6 Edge E12=2-8

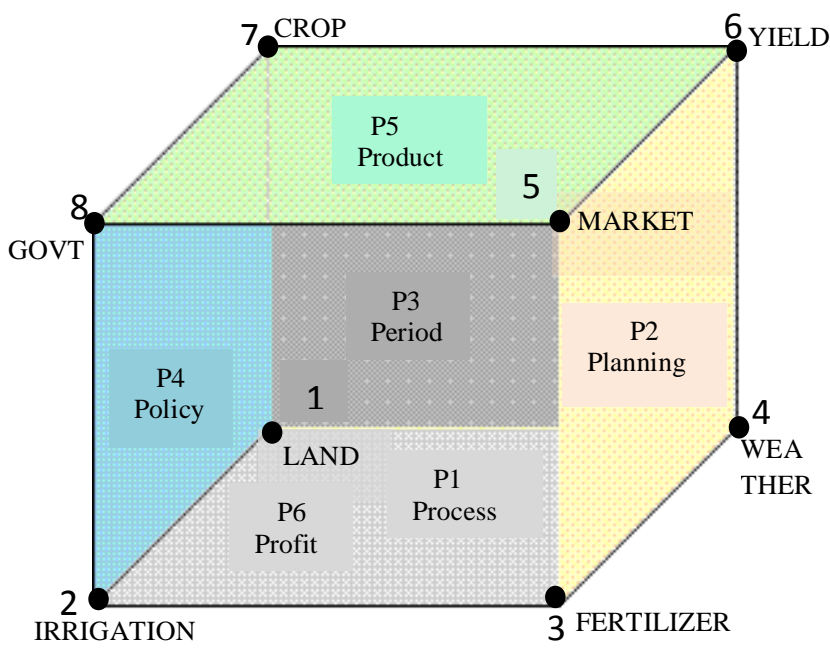

Figure 1. Agriculture Concept Cube

For example, at time $\mathrm{t}=\mathrm{t}_{0}$, the information phase of the client is in the Planning (Plane II) and he is retrieving information in the context of Machinery (Vertex). At time $t=t_{1}$, if he migrates the context to Crop, then the edges in the current plane such as "Market-Fertilizer, Fertilizer-Machinery, Machinery-Yield, YieldMarket" are taken into account and then the edges "Market-Govt. and Market-Yield" are considered since it leads to the crop context using just two edges in the concept cube. Now the new context point $\mathrm{f}(\mathrm{x} 1, \mathrm{y} 1)$ is compared with each edge and whichever edge will lead to crop context with minimal distance or time is chosen and used for context migration.

Table 1. Context Migration Table

\begin{tabular}{|l|l|l|}
\hline \multicolumn{1}{|c|}{$\begin{array}{c}\text { CONTEXT } \\
\text { POINT }\end{array}$} & CONTEXT EDGE & \multicolumn{1}{c|}{$\begin{array}{c}\text { CONTEXT } \\
\text { PLANE }\end{array}$} \\
\hline Land (L) & $\begin{array}{l}\text { P1E1, P1E4, P3E4, } \\
\text { P3E11, P4E1, P4E11, }\end{array}$ & $\begin{array}{l}\text { Process, Period, } \\
\text { Policy, }\end{array}$ \\
\hline Irrigation (I) & $\begin{array}{l}\text { P1E1, P1E2, P4E1, } \\
\text { P4E12, P6E12, P6E2 }\end{array}$ & $\begin{array}{l}\text { Process, policy, } \\
\text { profit }\end{array}$ \\
\hline Fertilizer (F) & $\begin{array}{l}\text { P1E2, P1E3, P2E3, } \\
\text { P2E5, P6E2, P6E5 }\end{array}$ & $\begin{array}{l}\text { Process, } \\
\text { Planning, Profit }\end{array}$ \\
\hline Weather (W) & $\begin{array}{l}\text { P1E3, P1E4, P2E3, } \\
\text { P2E6, P3E4, P3E6 }\end{array}$ & $\begin{array}{l}\text { Process, } \\
\text { planning, Profit }\end{array}$ \\
\hline Market (M) & $\begin{array}{l}\text { P2E5, P2E7, P5E10, } \\
\text { P5E7, P6E5, P6E10 }\end{array}$ & $\begin{array}{l}\text { Planning, } \\
\text { Product, Profit }\end{array}$ \\
\hline Yield (Y) & $\begin{array}{l}\text { P2E6, P2E7, P3E6, } \\
\text { P3E8, P5E7, P5E8 }\end{array}$ & $\begin{array}{l}\text { Planning, Period } \\
\text { Product }\end{array}$ \\
\hline Crop (C) & $\begin{array}{l}\text { P3E8, P3E11, P4E9, } \\
\text { P4E11, P5E8, P5E9 }\end{array}$ & $\begin{array}{l}\text { Period, Product, } \\
\text { policy }\end{array}$ \\
\hline Government (G) & $\begin{array}{l}\text { P4E9, P4E12, P5E9, } \\
\text { P5E10, P6E10, P6E12 }\end{array}$ & $\begin{array}{l}\text { Policy, Product }, ~ \\
\text { Profit }\end{array}$ \\
\hline
\end{tabular}

The client is retrieving information regarding one context only, that is in vertex level. For example, the queries like "what is the soil type in this location?" So the client is referring only to the Land context and the context point is present exactly at the Land vertex and it is a single dimension query.

In the edge level, the client is requesting information regarding two contexts at a time. For example, the client inputs a query as 
"which crops are feasible for this particular location?" So here the client refers to two contexts, Crop and Land and hence the context point is present somewhere on the edge connecting the Land and the Crop context.

When the client needs information regarding three contexts simultaneously, it lies in space level. For example, if the client sends a query as "How much irrigation should be done for this particular crop in this particular soil?" So the context point is present in the concept space between the Land, Crop, and Irrigation contexts. Hence the space level abstraction is used for three dimensional queries.

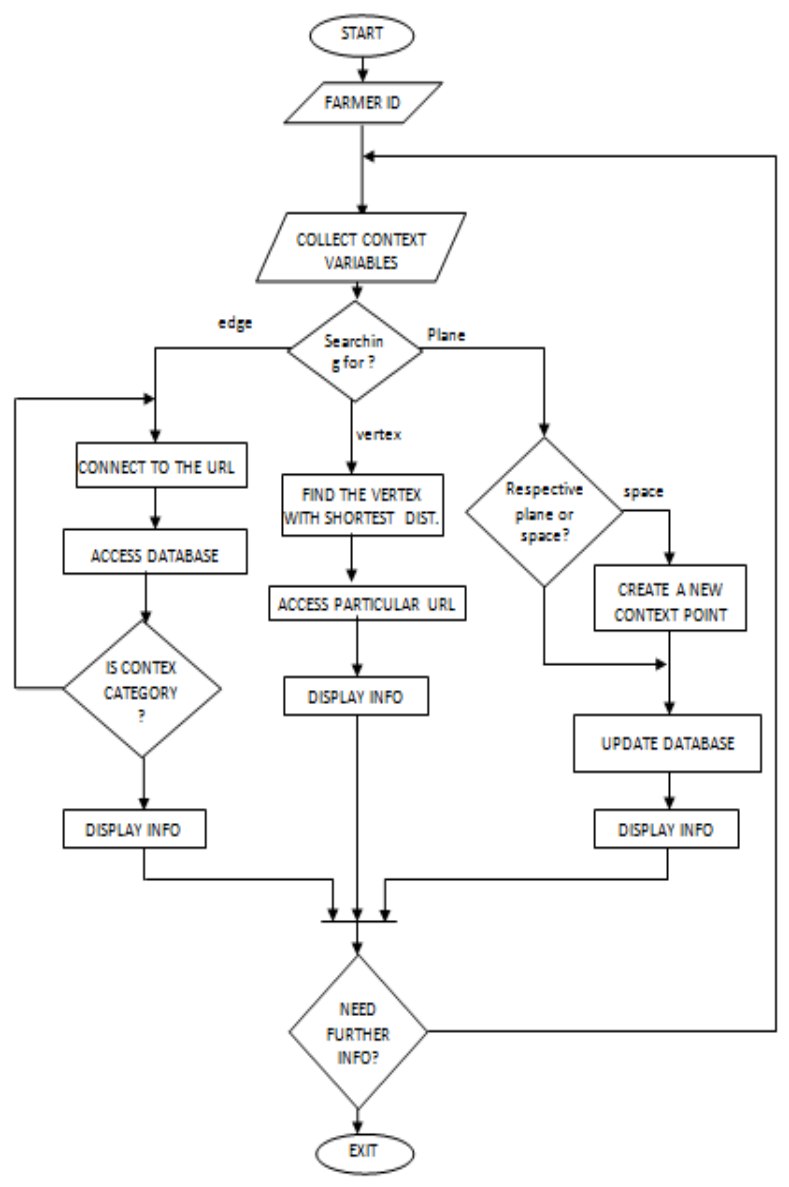

Figure 2. Activity Diagram

In the activity diagram shown in Figure, the client Id and context aware variables are collected. The context is checked for a edge or a plane or a vertex. If it's an edge the respective URL is connected. According to the context, required information is displayed. If the selection is a vertex, the shortest distance is calculated and traversed for the information. If the selection is plane, then the plane must be checked whether it is on a specific context point or in space. If in space a new context point is created and information is deployed.

\section{CONTEXT AWARE MOBILE SERVICES}

A context aware computing is an application's ability to detect and respond to environment variables. The user characteristics which are composed of static characteristics (language, first name,

etc) and of evolutive characteristics defined by his environment (his localization, time, etc) and his preferences, language are collected and stored in database [3]. Context awareness is achieved here by analyzing the user request and based upon that the data from the distributed databases stored in the servers are queried. The relevant information is retrieved and delivered to the user. It resides in local network and hence over heading of CPU can be prevented by keeping the frequently accessed information in cache. Location can be identified in terms of latitude and longitude, region and name of the mobile base station. As soon as GSMA device is switched on all the information are captured and verified with the client's database and authenticated to receive further information. No username and password is needed because it is not a security issue but it is a service issue. Let us say if any client needs information about crops feasible in his area he will

\begin{tabular}{|c|l|l|l|l|}
\hline Context & Event type & $\begin{array}{c}\text { Context } \\
\text { aware } \\
\text { computing }\end{array}$ & \multicolumn{1}{|c|}{ URL } & \multicolumn{1}{|c|}{$\begin{array}{l}\text { Mobile } \\
\text { services }\end{array}$} \\
\hline Land & Soil button & Suitable crops & $\begin{array}{l}\text { www.crops.er } \\
\text { ode.in }\end{array}$ & $\begin{array}{l}\text { Details about } \\
\text { the crops }\end{array}$ \\
\hline Farmer & ON button & $\begin{array}{l}\text { Major and } \\
\text { minor crops }\end{array}$ & $\begin{array}{l}\text { www.farmer.o } \\
\text { oty.in }\end{array}$ & $\begin{array}{l}\text { Farmers } \\
\text { productivity }\end{array}$ \\
\hline Weather & $\begin{array}{c}\text { Button 3 } \\
\text { pressed }\end{array}$ & $\begin{array}{l}\text { Rainfall } \\
\text { details }\end{array}$ & $\begin{array}{l}\text { www.weather. } \\
\text { com }\end{array}$ & $\begin{array}{l}\text { Amount of } \\
\text { rainfall }\end{array}$ \\
\hline Crop & $\begin{array}{l}\text { Button 1 } \\
\text { pressed }\end{array}$ & $\begin{array}{l}\text { pesticides and } \\
\text { fertilizers }\end{array}$ & $\begin{array}{l}\text { www.pesticid } \\
\text { es.gov.in }\end{array}$ & $\begin{array}{l}\text { pesticides and } \\
\text { place of } \\
\text { purchase }\end{array}$ \\
\hline Yield & ON button & $\begin{array}{l}\text { quantity per } \\
\text { acre }\end{array}$ & $\begin{array}{l}\text { www.farmer.o } \\
\text { oty.in }\end{array}$ & $\begin{array}{l}\text { Maximum } \\
\text { yield }\end{array}$ \\
\hline
\end{tabular}

just need to input the requirement for example 'crops', and the server will respond as per the context. Similarly various contexts are stored and computed in different environments with appropriate variables.

\section{Table 2. Mapping Of Context Awareness In Mobile Services}

Context-awareness appears as a promising idea for increasing usability of Web Information Systems using web service with mobile routers so that clients can access dynamic data as per requirement routed through the interface designed under AIS [1]. Here in the model, routing is not static. This dynamism helps in achieving the flexibility while arriving at the solution. The Agriculture Development Centre which acts as a service provider connected to the web serving needs of the client with variety of information from various respective sources. This is a client server based service where the client places the request and the distributed database present in the server responds to the client's request. This response is the information exactly in the context which the user has requested. The various contexts mapped in mobile services, event type, computing used for context awareness, its corresponding URL and mobile services are given in Table 2. For example in the weather context, when the event occurs connection is established and meteorological details from respective website is accessed and displayed on the user screen. A GSM based mobile network is planned with various base stations and mobile stations are kept in random locations within coverage limit and a migration centre which connects to satellite via ground 
station to access the information from the servers in agricultural development centers placed in different geographical locations as shown in Figure 3.

The middleware deal with the heterogeneous data plays a key role in consolidating data from multiple data centre of different platform and sending response to the special device that client holds. The Data concurrency is achieved by interlinking the remote web server with the help of an existing network. All distributed databases are updated regularly with the help of various context based services available across the globe.

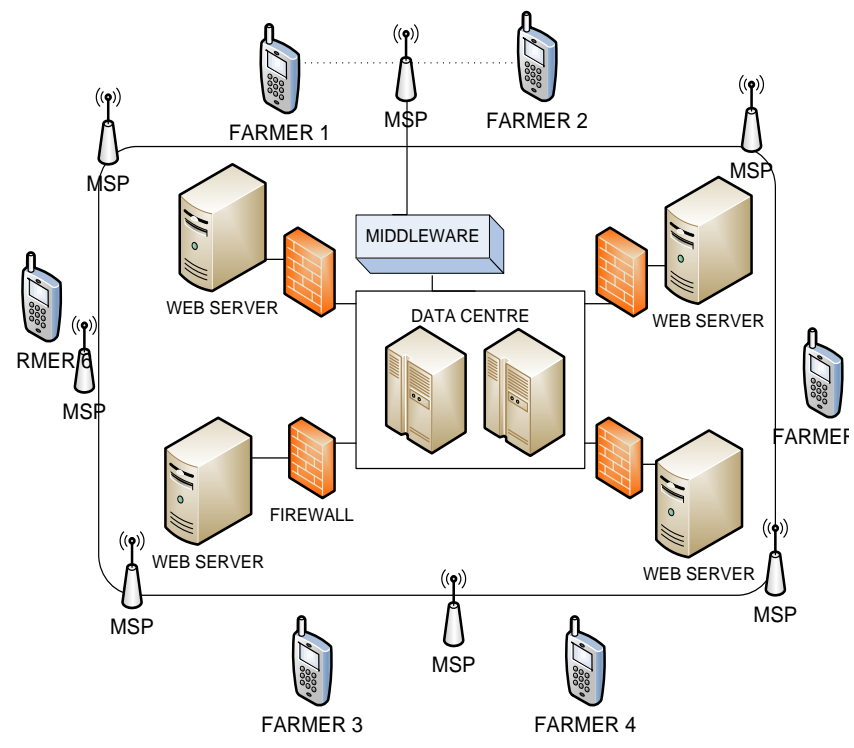

Figure 3. AIS architecture

\section{GSMA}

The proposed AIS model has been implemented with the special emulated device which may be called as Global System for Mobile Agriculture (GSMA).This model is fundamentally intended to serve the clients. Generally GSM network with six base stations (Mobile Service Providers-MSP) is used which acts as receptors of the user request and is responsible for establishing the connectivity between the migration station and the end user. The user request is then directed to the ground station which further takes to the satellite. From the satellite it is directed to another ground station placed at a remote location which is connected to four servers via a hub. These servers have distributed database which contains all the necessary details that a client would fundamentally require. The model is designed in such a way that it has context awareness and it is capable to retrieve the exact information which the client's needs. This helps the clients to take correct decision for carrying out their agricultural activities and ultimately resulting in high productivity with minimum effort. Also this will prevent clients to take wrong decisions for all their activities as the information provided to them not only tells them about what to use but also when to carry on all the important activities like sowing the crops and harvesting, irrigation, etc., along with the information on the quantity and the quality of the fertilizers and the pesticides that should be used, amount of water for irrigation purpose, etc.

The GSMA device as in Figure 4 that has been specifically proposed for the clients for this purpose has been designed to be highly user friendly with minimum interaction from the client. The device has a very few buttons for the functions such as ' $\mathrm{ON}$ ' and 'OFF' and some more buttons for the clients to select which information they want, like information on the crops, soil type, weather conditions, and fertilizers and pesticides. The relevant images are displayed on the buttons according to the information that will be retrieved. For example, if the client wants information about the weather then it is enough to just press the button having the image of sun on it which will retrieve the information. GSMA (Global System for Mobile Agriculture) device configurations are the challenges addressed in the work. The audio response and language feature can also be integrated.

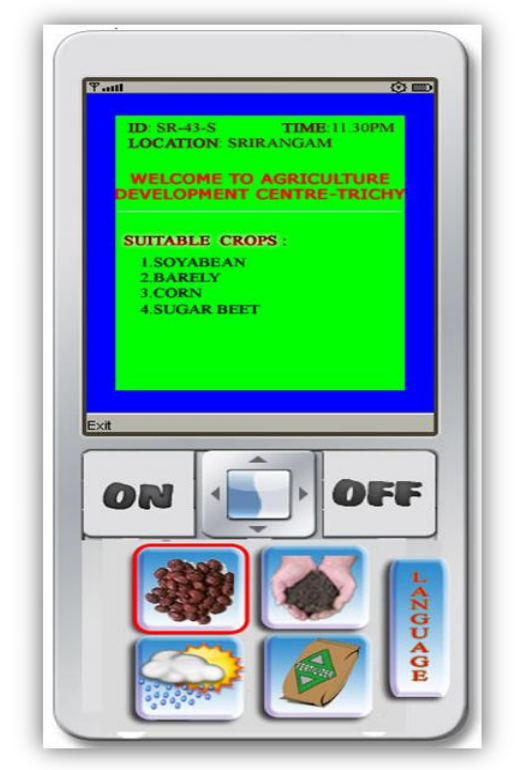

Figure 4.Proposed GSMA Device for farmers

\section{IMPLEMENTATION AND RESULTS}

The mobile web services are deployed with the help of http protocol using localized Apache Tomcat server through port 8080. For example, the crop service will receive a crop type request message of type string, operation getcrops is performed and the crops are listed. This will search the crop list based on location fetched from user ID database and accordingly crop details to be given. Server is designed using core java and front end mobile client application is developed using J2ME. The string data type is used for user authentication but password is not required from the user as it is service issue but not a security issue. Different methods such as crops details, market and weather have been implemented and by invoking an http service, application sends the request and receives the response from the server.

\section{SAMPLE CODE:}

// Module for getting the weather conditions based on Client's location private void findLocTemForecast(int id)throws Exception \{

String select $=$ "select Location,forecast,temperature from

UserDetails where id = "+id;

rs = stmt.executeQuery (select)

if(rs.next ()$)\{$

location = rs.getString("Location");

forecast $=$ rs.getString("forecast"); 
temperature $=$ rs.getInt("temperature");

\}

\}

private void soilType()throws Exception \{

// Crops based on the climate and temperature

Location = "' +location+"'";

String soilinfo $=$ "select soil from Soil where

rs = stmt.executeQuery(soilinfo);

if(rs.next())\{

soiltype = rs.getString("soil");

\}

\}

Exception \{

private void cropClimateTemperature()throws

// short list the crops based on the soil type ---

String cropselect $1=$ "select crop from

CropTemp where ( temperature $1<="+$ temperature + "or

temperature $2>=$ " +temperature + " ) and climate $=$ " +forecast

+"'"';

rs = stmt.executeQuery(cropselect1);

while(rs.next())\{

crop_temp.add(rs.getString("crop"));

\}

\}

private void cropSoil()throws Exception\{

String cropselect $=$ "select crop from CropSoil

where soil 1 = "'+soiltype +"'or soil2 = "' +soiltype +"' or soil3 = "' +soiltype +"'";

rs = stmt.executeQuery (cropselect);

while(rs.next())\{

\}

crop_soil.add(rs.getString("crop"));
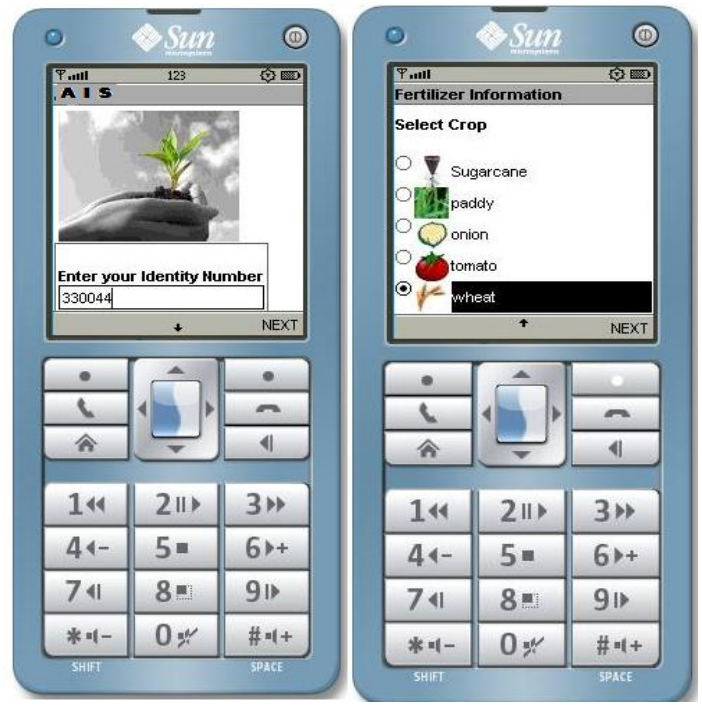

Figure 5. Implementation Snapshots

It is a multi tier application consisting of mobile client application, resources, components and containers. Mobile client is developed with J2ME so the application can be installed in wide range of mobile phones. The derived classes of Screen Class like ImageItem, TextField, ChoiceGroup is used to create high- level J2ME displays. The Choice items are in pictorial representation. So it is easier for the client to understand. The mobile client requests services from the web server using HTTP POST. Servlets are used to process the clients request and response back. Authentication module is included to authenticate the clients request and find the location of the client. Decision is made do provide right type of services to the clients request. Weather information of the client is found using weather.com's XML data feed. Set of java classes is used to parse the $\mathrm{xml}$ document which is received from weather.com and find the weather information.

\section{CONCLUSION}

The model of AIS is designed in such a way that it should be wide in scope with very minimal cost. The proposed model can be extended to the entire state as well as the country as it is the need of the hour. Government may come forward to sponsor the GSMA device to the client instead of too many other subsidies. small scale clients may be charged less compared to the medium and large scale clients. Multi lingual query and response services as additional interfaces are to be incorporated as an additional service and deployed in the Agricultural Development Centre. Integrating with other regional networks it is possible to predict the water release from the nearby reservoir. Any global network can also be shared to get the information regarding the frightening diseases like bird flu, cattle fever, etc. To lessen the load on the client audio response can also be made available through broadcast in emergency conditions as additional refinement.

\section{REFERENCES}

[1].Aleksander Binemann-Zdanowicz, Roland Kaschek , KlausDieter Schewe, Bernhard Thalheim "Context-aware Web Information Systems" Proceedings of the first Asian-Pacific conference on Conceptual modelling - Volume 31,page 37$48,2004$.

[2] Ariel Pashtan, Remy Blattle, Andi Heusser, Peter Scheuermann, "CATIS: A Context-Aware Tourist Information System",International workshop of mobile computing, June2003.

[3] B. Soukkarieh, and F. Sedes, "Towards an Adaptive Web Information System Based on Web Services," The Fourth International Conference on Autonomic and Autonomous Systems ICAS 2008, Gosier, Guadeloupe,March 16-21, 2008.

[4] Moran, T., and P. Dourish. Introduction to this special issue on context-aware computing.. Human-Computer

Interaction, 16:87-95, 2001.

[5] Ta Duy Thang, Matsuda H., Kanasugi H., Sakakibara H., Tsuruoka M., Shibasaki R, "Self-Information System: A contextaware scheduler with visualization module based on selfinformation"Asian conference on remote sensing,2005 